\title{
ELECTRO-CLINICAL PROFILE OF 117 DEEP CEREBRAL TUMORS
}

\author{
Joyce Graham Small, M.D. ${ }^{1}$, B. K. Bagchi, Ph.D. and Kenneth A. Kooi, M.D. \\ The Neuropsychiatric Institute, University of Michigan, Ann Arbor, Mich. (U.S.A.) ${ }^{2}$
}

(Received for publication: July 8,1960 )

Many studies report clinical and EEG findings in tumors of deep cerebral structures. It is contended in the main that clinical and radiological data are more useful for diagnosis and localization of such lesions than EEG findings. Workers largely agree on the character and localizing value of EEG in patients with tumors in or near the upper convexity of the brain but they report varied opinions in regard to the deep lesions.

One could cull several dozen cases of deep intra-cerebral tumors out of mixed reports in which EEG findings have been described as not outstanding or as not definitely outside normal limits (Broglia and Postir 1956a, b; Daly et al. 1953; Van der Drift 1957; Jus et Jus 1947; Klass and Bickford 1958; Lairy-Bounes et DreyfusBrisac 1950; Lam 1950; Londoño 1957; Longo et al. 1950; Magnus and Van der Drift 1957; McDonald and Korb 1940; Paillas et al. 1948; Parat 1948; Silverman and Graff 1957; Schlesinger and Strauss 1947; Tönnis et al. 1953; Walter and Dovey 1944; Williams 1939). Investigators have found what they consider diffuse and ili-defined EEG abnormalities in these lesions (Bagchi and Bassett 1943; Daly et al. 1953; Longo et al. 1950; Schlesinger and Strauss 1947; Williams and Gibbs 1939). Homolateral alpha depression (Bucy and Case 1940; Case 1940), bilateral alpha bursts (Cobb 1944), fast waves (Cordeau 1959), 14-6/sec positive spikes (Stephenson 1951) have been mentioned.

1 Present Address: Department of Psychiatry, University of Oregon Medical School, Portland, Oreg. (U.S.A.).

2 Acknowledgement is due to the Departments of Neurology and Neurosurgery, University of Michigan Medical School. Appreciation for technical help is due to Miss Hazel Calhoun. Aided by a grant B-1805 from the National Institute of Neurological Diseases and Blindness, United States Public Health Service.
Some consider EEG localization unsatisfactory in such lesions (Cuneo and Rand 1950; Hoefer et al. 1946; Lairy-Bounes et Dreyfus-Brisac 1950; Schlesinger and Strauss 1947; Walter 1940). Non-specific value of EEG as affording a basis for further investigation has been conceded by others. Quite a few authors consider bilaterally synchronous theta or theta-delta bursts as being associated with deep lesions (Cobb 1944, 1957; Cuneo and Rand 1950; Daly et al. 1953; Van der Drift 1957; Inghirami et Capdevielle 1954; Jasper and Van Buren 1953; Jus et Jus 1947; Lairy-Bounes et Dreyfus-Brisac 1950; Londoño 1957; Longo et al. 1950; Paillas et al. 1948; Parat 1948; Silverman and Graff 1957: Stephenson 1951; Terzian and Cecotto 1954; Tönnis et al. 1953; Walter and Dovey 1944), and some of them have reported bilateral delta discharges as well (Bickford 1957; Broglia and Postir 1956 b; Cordeau 1959; Cuneo and Rand 1950; Daly et al. 1953; Van der Drift 1957; Inghirami et Capdevielle 1954; Jasper and Van Buren 1953; Jus et Jus 1947; Lairy-Bounes et Dreyfus-Brisac 1950; Laufer 1947; Longo et al. 1950; Paillas 1948; Silverman and Graff 1957; Terzian and Cecotto 1954; Walter 1937; Walter et al. 1939; Williams 1939). The socalled "distant rhythms" in deep lesions and their implications have been dealt with by several workers (Cobb 1957; Faure et al. 1951; Jasper and Von Buren 1953).

It is often not evident from the literature surveyed what amount of emphasis was placed by the authors upon their EEG findings in these deep tumors in order to guide the clinician and the surgeon. Neither is it always clear whether these EEG signs alone were regarded as sufficient to justify a diagnosis of a deep lesion. Nor is it clear whether some additional EEG factors on the one hand or some clinical findings limiting 
the application of EEG factors on the other were considered to guard against misleading information. Some passing mention has been made in this connection by others (Bickford 1957) since our earlier report (Bagchi et al. 1952).

The value of the EEG in such a situation can best be appraised on the basis of adequately gathered and treated data on a large series of cases. In our study of such lesions for over 15 years, certain EEG clues have emerged which have been structured and added to those found in the literature. These have been utilized in an attempt to rule out a focal superficial lesion of the upper convexity and to rule in a deep disturbance or lesion, without necessarily trying to identify the involved structures (Bagchi 1955a, b; Bagchi et al. 1952). This was done without any prejudice to the legitimate thinking that management, final diagnosis or disposition of a case will depend not on EEG findings alone, but on the integrated evaluation and proper weighting of all clinical and laboratory data.

The present study is an attempt ( $a$ ) to discover any possible specificity of correlation between "distant EEG discharges" and clinico-anatomical data, and $(b)$ to assess the degree of success or failure in the application of EEG clues to depth diagnosis.

\section{MATERIALS AND METHODS}

From 1941 to June of 1958,117 patients were selected who had cerebral tumors situated at least $2 \mathrm{~cm}$ and generally more in depth from the cortex. All patients had been extensively studied from a clinical point of view and had received an EEG examination prior to contrast studies and surgery. Patients with tumors in the cortex or primarily in the temporal lobe, or in infratentorial structures were not included. Within the context of our present purpose the first two groups were omitted in this study because many of these were reported by us elsewhere (Bagchi $1955 \mathrm{a}, \mathrm{b}$; Bagchi and Bassett 1943, 1947) and because temporal tumors show, as a rule, relatively homogenous lateralizing EEG features. The infratentorial series is worked up in another study (Bagchi et al. 1961). Detailed information regarding 60 clinical and EEG variables were gathered in each case. 68 patients were males and 49 were females. Duration of symptoms ranged from under one month in 10 cases, one to twelve months in 60 cases, to more than one year in 47 cases. Contrast studies, i.e., pneumoencephalography, arteriography and/or ventriculography, were done in 95 per cent of the cases. All tumors were verified by surgery and or autopsy. Approximately one-third of the cases (41) came to postmortem.

The patients were judged to have increased intracranial pressure (IICP) if one or more of the following signs were present: papilledema, ventricular dilatation with or without asymmetry, increased cerebro-spinal fluid pressure, separation of sutures, and/or evidence of increased

TABLE I

EEG in deep tumors in relation to their histological types

\begin{tabular}{|c|c|c|c|c|c|c|c|}
\hline Type & Total & Normal & Borderline & $\begin{array}{c}\text { Mildly } \\
\text { abnormal }\end{array}$ & $\begin{array}{l}\text { Moder- } \\
\text { ately } \\
\text { abnormal }\end{array}$ & $\begin{array}{l}\text { Markedly } \\
\text { abnormal }\end{array}$ & $\begin{array}{c}\text { Correct } \\
\text { depth } \\
\text { diagnosi } \\
\text { by EEG }\end{array}$ \\
\hline Glioblastoma & 25 & 0 & 2 & 2 & 11 & 10 & 18 \\
\hline Astrocytoma & 23 & 0 & 0 & 3 & 12 & 8 & 14 \\
\hline \multicolumn{8}{|c|}{ Craniopharyngioma and pituitary } \\
\hline $\begin{array}{l}\text { adenoma } \\
\text { Meningioma }\end{array}$ & 20 & 1 & 2 & 4 & 8 & 5 & $\begin{array}{l}14 \\
16\end{array}$ \\
\hline Meningioma & 18 & 0 & 0 & 2 & 4 & 12 & 16 \\
\hline Oligodendroglioma & 8 & 0 & 0 & 1 & 4 & 3 & 6 \\
\hline Spongioblastoma polare & 6 & 0 & 2 & 2 & 0 & 2 & 2 \\
\hline Pinealoma & 5 & 0 & 0 & 0 & 2 & 3 & 5 \\
\hline Miscellaneous & 12 & $\mathrm{C}$ & 2 & 2 & 6 & 2 & 10 \\
\hline TOtALS & 117 & 1 & 8 & 16 & 47 & 45 & 85 \\
\hline Percentage & 100 & 0.9 & 7.1 & 14 & 40 & 38 & 73 \\
\hline
\end{tabular}


TABLE II

Some clinical and EEG findings in deep tumors in relation to their location

\begin{tabular}{|c|c|c|c|c|c|c|c|c|c|c|c|c|}
\hline A & $\mathrm{B}$ & $\mathrm{C}$ & D & $\mathrm{E}$ & $F$ & $\mathrm{G}$ & $\mathrm{H}$ & I & $\mathbf{J}$ & $\mathbf{K}$ & $\mathrm{L}$ & M \\
\hline Tumor location & 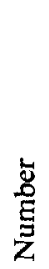 & 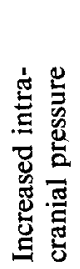 & 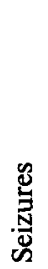 & 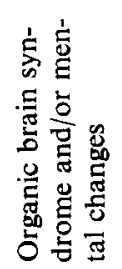 & 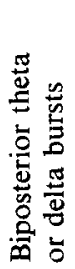 & 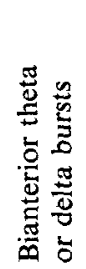 & 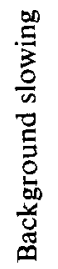 & 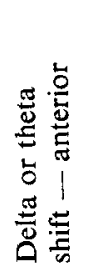 & 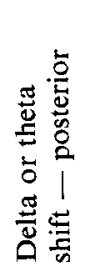 & 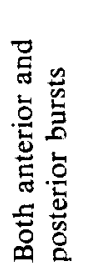 & 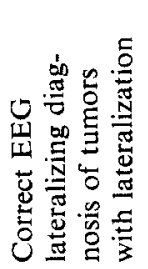 & 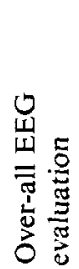 \\
\hline
\end{tabular}

I. Olfactory groove meningioma 14

Sub-frontal

Sub-frontal chiasm

$\begin{array}{lll}9 & 5 & 3\end{array}$

7
2

$\begin{array}{lllll}1 & 8 & 2 & 3 & 0 \\ 2 & 5 & 1 & 1 & 1 \\ & & & & \\ 4 & 4 & 5 & 2 & 1 \\ 5 & 5 & 7 & 1 & 3 \\ 1 & 1 & 1 & 0 & 0 \\ 3 & 1 & 3 & 1 & 2\end{array}$

$8 / 9 \quad{ }^{0} 0_{0} 0_{11}$

II. Chiasmatic tumors

Chiasm
C, IIIV, T
C, Adj. W. M.
C, Adj. W. M., IIIV, T

III. Ventricular tumors Post, IIIV, T

L. V.

IIIV, L.V., T

V, Adj. W.M., T

32
18
8
3
3

$\begin{array}{lll}7 & 6 & 4 \\ 4 & 0 & 2 \\ 0 & 1 & 0 \\ 2 & 1 & 3\end{array}$

$\begin{array}{rrrr}31 & & & \\ 4 & 4 & 1 & 3 \\ 1 & 1 & 0 & 0 \\ 5 & 4 & 1 & 4 \\ 21 & 10 & 12 & 11\end{array}$

3
0
1
5

$\begin{array}{ll}2 & 2 \\ 0 & 0 \\ 1 & 1 \\ 6 & 4\end{array}$

$$
9 / 16 \quad 1_{310},
$$

IV. Basal ganglion tumors $\quad 19$ B.G., V. T
B.G., Adj. W.M.

6
2

4
2
9

4
1
4

1
2
5

3
1
5

2
1
4

$\begin{array}{lll}0 & 0 & 1 \\ 0 & 0 & 1 \\ 1 & 1 & 4\end{array}$

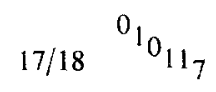

V. Corpus callosum tumors CC, Adj. W.M.
CC, W.M., V, T
CC. W.M., B.G.

13

5
7
1

5
4
1

3
4
0

$\begin{array}{ll}3 & 2 \\ 5 & 2 \\ 1 & 0\end{array}$

$\begin{array}{lllll}3 & 2 & 1 & 1 & 1 \\ 6 & 1 & 1 & 1 & 2 \\ 0 & 0 & 0 & 0 & 0\end{array}$
$9 / 9$

VI. Tumors of subcortical white matter alone

Total
Percentage

\begin{tabular}{|c|c|c|c|c|c|c|c|c|c|c|}
\hline 8 & 5 & 6 & 7 & 4 & 5 & 2 & 1 & 0 & 4 & $8 / 8$ \\
\hline 117 & 69 & 48 & 60 & 42 & 63 & 40 & 19 & 12 & 34 & $73 / 86$ \\
\hline 100 & 59 & 41 & 51 & 36 & 54 & 34 & 16 & 10 & 29 & 85 \\
\hline
\end{tabular}

$\mathrm{C}=$ Chiasm (with or without intrasellar involvement) $\mathrm{V}=$ Ventricle; $\mathrm{T}=$ Thalamus; $\mathrm{L.V}$. = Lateral ventricle; W.M. = White matter; $\quad \mathrm{CC}=$ Corpus callosum. Column $\mathrm{M}$ : Slanting figures $=$ Total number of normal, borderline, mildly abnormal, moderately abnormal and markedly abnormal EEG's in each tumor location group.

pressure at operation. The exact location and extent of some deep tumors with sub-total removal and without postmortem presented a formidable problem. In such cases all the available clinical, roentgenological and surgical data were pooled to arrive at as close an estimate of the location as possible. Arbitrarily, areas of involvement were selected to comprise the major groups I to VI, with additional extension noted under each (Table II). As all pituitary adenomas had chiasmatic involvement, they were put under group II, Table II, and one hypothalamic tumor with extension to chiasm, III ventricle, and thalamus was also put under the same group, subgroup II. Mental changes included organic brain syndrome and personality aberrations traceable to lesions.

19 cases were studied on a 3-channel and 11 
cases on a 6-channel EEG instrument with incomplete technique by present day standards. The remainder (87) were examined on an 8channel Grass instrument. In all but 5 cases, a detailed EEG study using 23 or more scalp electrodes in as many as 26 monopolar and bipolar, short and long distance, montages of 2 or more minutes each was performed. The technique has been elaborated elsewhere (Bagchi $1955 \mathrm{a}, \mathrm{b}$ ). In about three-fourths of the cases, the elaborate technique was found to give independent or confirmatory information not obiainable from our routine 7 to 10 montages used in the first part of each record. The rationale for the prolonged work-up was to obtain longer samples to identify transient abnormal discharges and to utilize different reference leads in different epochs for the same scalp leads for manipulating $(a)$ pushpuli cancellation, (b) phase, and ( $c$ ) inter. electrode distance factors. EEG's were interpreted on the basis of previously developed electroclinical correlational matrices (Bagchi $1955 \mathrm{a}, \mathrm{b}$ : Bagchi et al. 1945).

The empirical EEG clues for depth diagnosis of a deep lesion included one or more of the following: synchronous bianterior (bimotor with or without biprefrontaly and/or biposterior delta, theta, o: alpha bursts, inter-hemispheric shifting bursts between homologous regions anteriorly or posteriorly, biantero-posterior parasagittal burst variability and /or bi-parasagit. tal-lateral burst variability (asynchronous appeaiarce of bursts), overall unihemispheric emphasis of episcdes of voltage increase and/or wavelength decrease of bilateral synchronous or shifting bursts, widespread interareally variable bursts in the same hemisphere against a reasoniably good background, and slow background (Bagchi 1955 a, b: Bagchi et al. 1952). Differential weighting of these clues was not done though the first few seemed to be more important. Sometimes it was difficult to distinguish burst activity from background activity. The bursts were considered minimal if they appeared 4-6 times of one or more sec each, moderate if $7-10$ times, or marked if 11 or more limes in a record. Our calculations are based on moderate and/or marked bursts only. Background EEG slowing and burst phenomena (over 50 per cent increase of background voltage in sudden epi- sodes of any wave length) have been separately categorized. Homologous shifting bursts are sometimes called independent bursts in the literature but they should not be confused with random diffuse discharges.

On the basis of several thousand control cases as mentioned before (Bagchi et al. 1952) and additional cases studied later, some of the factors limiting depth diagnosis by EEG were considered to be "degeneration", damage, inflammation, hypertensive encephalopathy, post-1raumatic states, advanced metabolic or extra-cerebral diseases and vascular conditions which may show some of the above-mentioned EEG signs. Epilepsy with bilateral, shifting or other EEG signs would not be considered as a truily limiting factor in deep cerebral diagnosis. Its presence (and as a matter of fact, the presence of the previously mentioned conditions) would, however definitely compicate an EEG interpreter's choice between a difflise abnormal condition with or withoui a focal emphasis, a deep patho-physiological irigger or iriggers and a deep macroseopic expanding lesion. If there was a doubt anout the absellce of any of the abovementioned clinical limiting factors in a particular case, depth diagnosis hy FFG alone was heid in consequence rather uncertan or inapplicable.

RESUTS

Tabl: I show the degree of EEG abnormality and accuracy of depth diagnosis in relation to tumer types. Table Il illustrates the location of tumors and relates this to some clinical and $\mathrm{FEG}$ findings. Tabie III reiutes age to some of these fridings. Increased intracanial prosure (IICP) occurred in more than half of the cases $(59 \%)$ (Table II, C). There is no single tunor site with a strong predilection for the development of increascd iniracranial pressure. On the contrary, there is a trend suggesting that some siles are less associated with IICP. Fo: example, fewer chiasmatic tumors ( 13 out of $32,41^{\circ}$, ) with or without involvement of neighboring locations (Table II, group II) tended to be associated with IICP than tumors in other locations (range 41$79 \%$, median of six groups being $62 \%$ ). Also a smaller number of chiasmatic tumors $\left(56^{\circ}\right)$ showed moderate to marked EEG abnormaity than tumors situated elsewhere (range $56-100^{\circ} \%$, 
TABLE III

Some clinical and EEG findings in deep tumors in relation to the age of patients

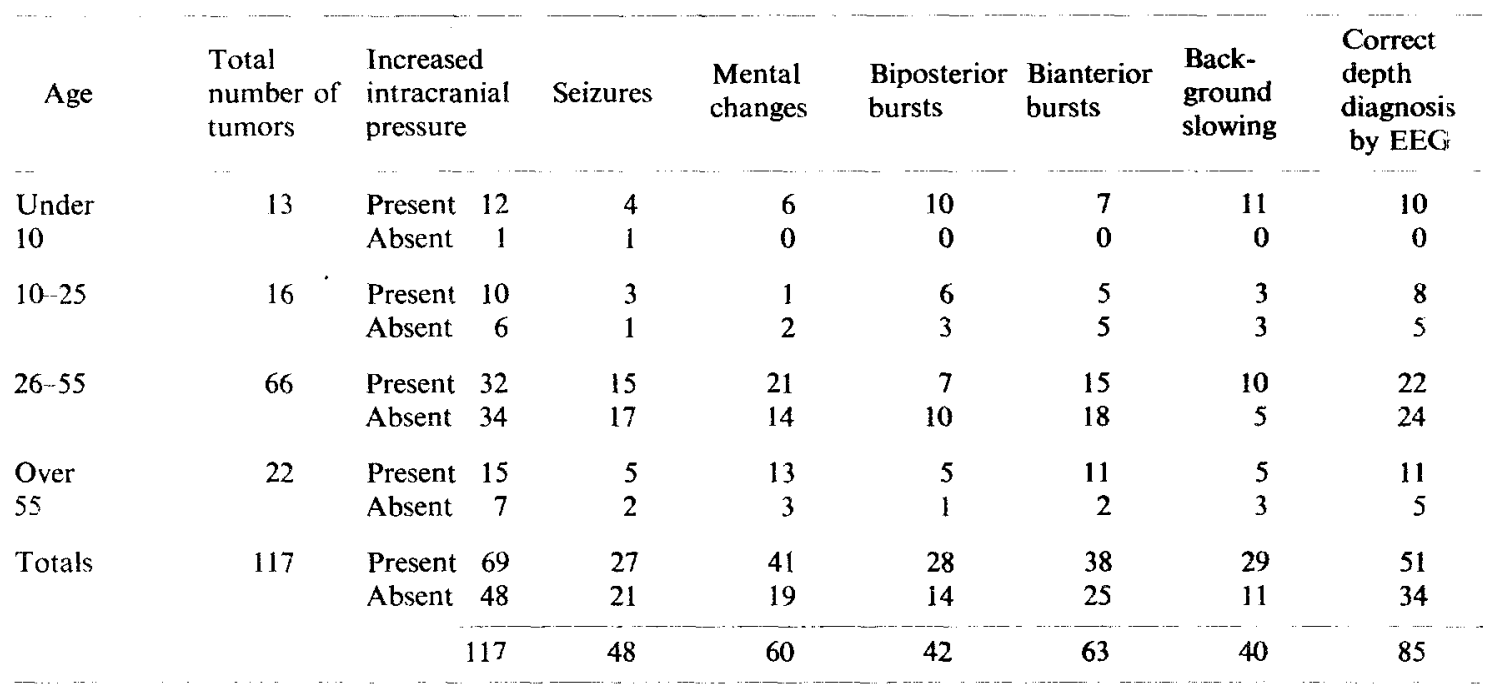

median of six groups being $90 \%$ ) (Table II, M). Further, these tumors in group Ir had the least association with seizures ( 8 out of 32 ) as compared with tumors in other locations. 41 percent of the total series had produced seizures of one type or another (Table II, D). However, this trend is reversed if only the chiasm subgroup is taken. Association in the group II with mental changes is lower ( 9 out of $32,28 \%$ ) than in other groups (range $28-87 \%, 60 \%$ being the median of the six groups) (Table II, E). On the other hand, the chiasmatic tumors display some localizing clinical and laboratory signs, seen less frequently in non-chiasmatic tumors. To illustrate, the figures for the two groups are: eye signs (atrophy, field defect) 73 vs. 30 per cent, endocrine signs - 41 vs. 18 per cent, and abnormal sella turcica in skull X-rays -60 vs. 39 per cent (not shown on Table 11). Background slowing (mixed thetaalphas, prominent thetas or deltas, not bursts) in chiasmatic tumors, with or without intrasellar involvement (not including thalamic and ventricular extension) is the same (5 out of 18 , $28 \%)$ as the median of the six groups, $(28 \%$, range being $22-50 \%$ ) (Table $\mathrm{II}, \mathrm{H}$ ). But when ventricular and thalamic extensions of chiasmatic tumors are included, background slowing becomes proportionally high ( 16 out of $32,50 \%$ ). This increase may be adventitious or it may be accounted for by the involvement of thalamic or other neighboring regions. But when all cases with thalamic involvement are compared with those without, in relation to background slowing, there is no statistically significant correlation. This appears strange in view of the generally accepted association between alpha waves and the integrity of the antero-mesial thalamus. Only 22 per cent of chiasmatic tumors including pituitary adenomas but without neighborhood involvement show bianterior bursts (range of all groups $22-92 \%$, median $52 \%$ ). These tumors show about the same percentage of biposterior bursts (range $22-64 \%$, median of all groups $31 \%$ ).

Increased intracranial pressure appears to be present in children under 10 (12 out of 13) more than in older age groups (Table III). This relation between IICP and age (in our context downward age gradation) over the entire series is statistically significant $\left(X^{2}=9.66, P<0.02\right)$ as is the correlation between IICP and background slowing $\left(X^{2}=4.6, P 0.02-0.05\right)$. After correcting for age norms, background slowing vs. age approaches significance $\left(X^{2}=8.99, d f=3, P\right.$ $0.02-0.05$ ), so does the relation between IICP and mental changes $\left(X^{2}=4.5, P<0.05\right)$ for the total group.

47 of the patients had moderately abnormal and 45 profoundly abnormal EEG's. 16 had mildly abnormal and eight borderline EEG's (Table I). Only one patient had a normal EG. 
This was a patient with a craniopharyngioma near the midline. Of the 25 patients comprising the loss disturbed EEG groups, 14 had chiasmatic tumors with or without extension else- have increased intracranial pressure (Table II, group I, F). Chiasmatic tumors without subfrontal involvement do not usually show this picture of bifrontal deltas (Bagchi $1955 \mathrm{a}, \mathrm{b}$ );

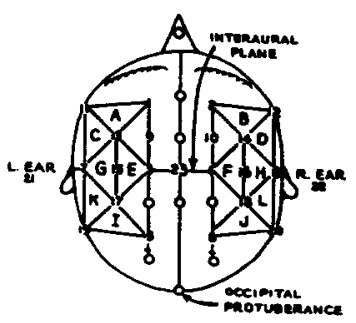

\section{OLFACTORY GROOVE MENINGIOMA}

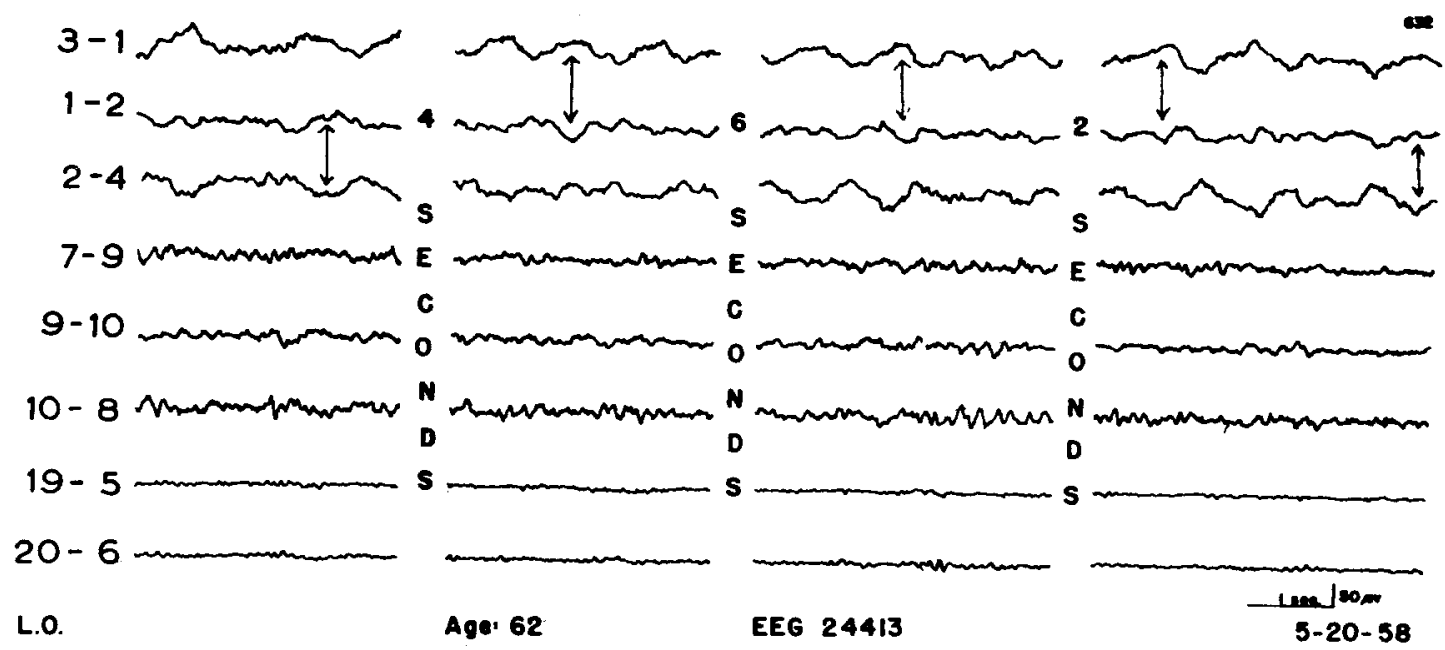

Fig. 1

Olfactory groove meningioma, midline, more on right than on left. Headache and organic brain syndrome for many years. Bilateral anosmia, constricted visual fields. No increased intracranial pressure. Ventriculogram abnormal without dilatation. Special transverse recording emphasizes shifting delta phase reversal between two prefrontal regions (see arrows). 11/1, 1/2, 2/12 linkages are also possible for transverse recording, although these may have certain disadvantages due to extraneous corneoretinal field disturbances in leads 11 and 12. This type of shifting delta phase reversal in these special linkages involving prefrontal regions has been found empirically to suggest a deep lesion (especially subfrontal), and not an upper convexity anterior sagittal or parasagittal lesion. This discrimination of depth is not as secure when one has only biprefrontal delta bursts to go by in ordinary monopolar or antero-posterior parasagittal bipolar linkages.

Some uniprefrontal delta focal bursts on the right were also present in this case (not shown). There were no delta waves posterior to interaural line.

Time and voltage calibration in the right lower corner in this and other figures. True occipitals are empty circles in the head diagram posterior to leads 5 and 6 and are usually employed as such.

where. Moderately or markedly abnormal EEG's occurred in association with tumors in all locations, most prominently in olfactory groove meningiomas $(100 \%)$ (Pavlovski 1958). These tumors pressing against the inferior surface of the frontal lobes occupied a special group showing marked bianterior deltas with posterior part of the brain free, except in 3 cases. These 3 cases with biposterior theta-delta bursts did not with subfrontal involvement they do (Fig. 2). There are exceptions. The following case illustrates that large pituitary and chiasmatic lesions may give rise to only minor EEG alterations:

C.G. - 49 year old white male. Failing vision, polyuria and polydypsia for five years. Blind O.S. and temporal field loss O.D. Skull X-ray revealed sellar erosion. Pneumoencephalogram outlined a suprasellar lesion. At operation a large 
intrasellar chromophobe adenoma with some extension to the inferior frontal area and involving the chiasm and probably neighboring regions was subtotally resected. Preoperative EEG was borderline with slight alpha background suppression on the right.

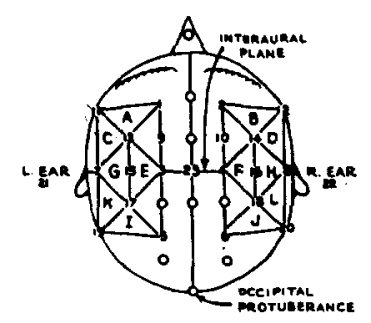

involvement of the source of projection pathways in the involved side, differential edema, or obscuration of lateralizing signs by generalized signs may play variable roles in these false negative or undetected EEG lateralizations.

Moderate to marked inter-hemispheric shift

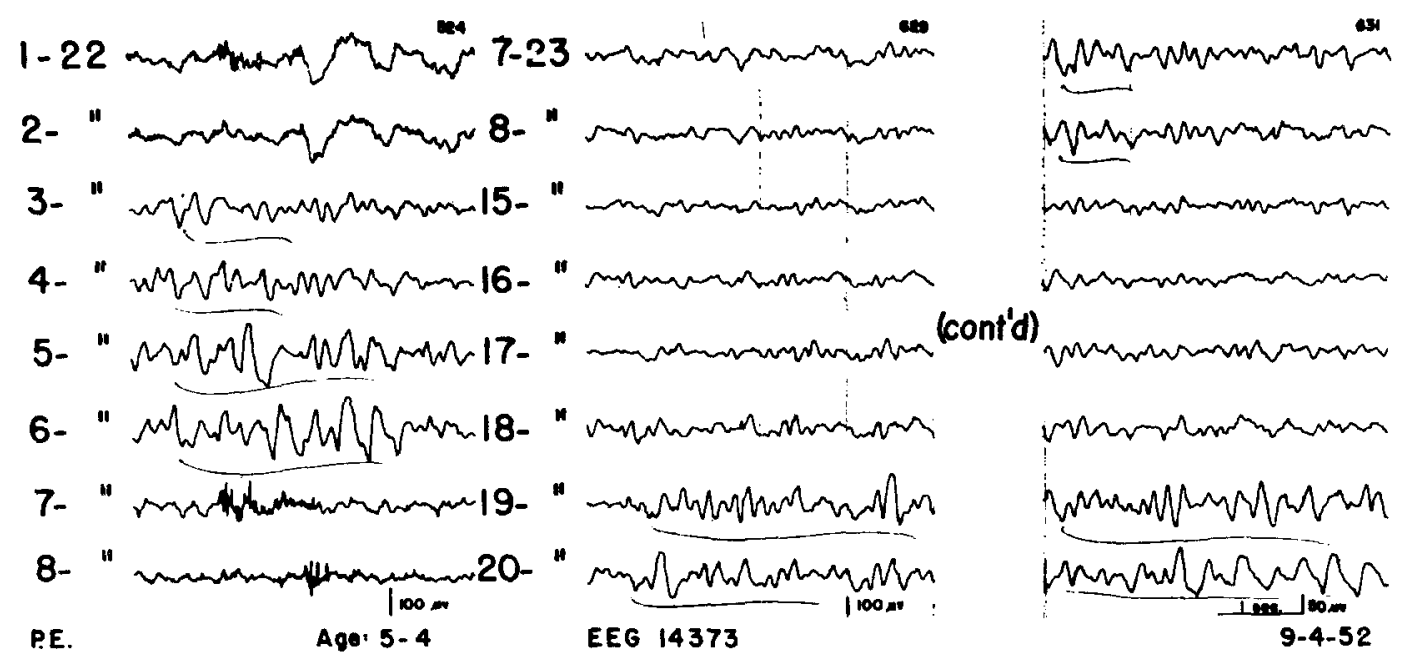

CRANIOPHARYNGIOMA CHIASM, SUB-FRONTAL

Fig. 2

Golf ball sized craniopharyngioma involving chiasm and third ventricle, midline with right sided extension. Papilledema, headache, nausea and vomiting. Visual fields untestable. EEG background slightly slow occasionally. Irregular theta-delta bursts are seen often and are chiefly in biposterior regions, a little more on the right (last lines, panel 3). In this case, the biprefrontal regionsdo not show bursts. There are some bimotor theta bursts (lines 3 and 4, panel 1).

Correct EEG lateralizing signs were found in $73(85 \%)$ out of 86 deep tumors, purely lateral or midline with lateral extension (Table II, L). Of the remaining 13 EEG's, EEG lateralization was completely false in 3 and no lateralization was obtained in 10. Of those which were erroneously lateralized, one was in the chiasm, a second in the right lateral ventricle, thalamus and III ventricle, and the third in the left lateral ventricle and white matter. The reasons for these failures are obscure. Contralateral pressure, pathophysiological inter-hemispheric imbalance, expressed transiently in the uninvolved side, non- of bursting thetas and deltas between homologous regions, either anterior or posterior, occurs (Table II, I, J) in approximately the same proportions $(16 \%$ and $10 \%)$ in deep supra-as in 121 infratentorial lesions (Bagchi et al. 1961). However, if one includes mild shift phenomenon relating to all types of waves (not shown on Table II) supratentorial lesions show significantly less incidence of it than infratentorial lesions (shift between anterior homologous regions of the two hemispheres: 41 vs. 79 per cent, shift between posterior homologous regions of the two hemispheres: $24 \mathrm{vs}$. 
48 per cent). In our experience inter-hemispheric shift phenomenon is not very common in cortical lesions. It may occur when these lesions are large enough to touch corpus callosum, roof of the III ventricle or other deeper sites.

Antero-posterior variability of waves of all somewhat different, but not significantly so, from what is found in posterior fossa tumors (42 vs. 46\%) (Bagchi et al. 1961). However, there is no statistically significant correlation between either location of bursts and IICP $\left(X^{2}=0.1, P 0.70-0.80 ; X^{2}=1.2, P 0.20\right.$ -

\section{CRANIOPHARYNGIOMA CHIASM, \& III VENT.}

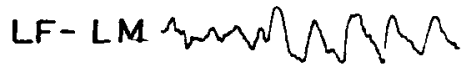

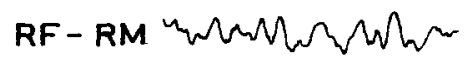

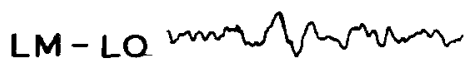

$$
\begin{aligned}
& \text { RM- RO und Nuruturs } \\
& \text { LT - LM MNY Nonmo }
\end{aligned}
$$

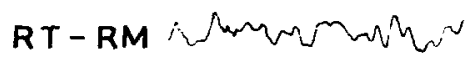

$$
\begin{aligned}
& \text { LT - LO MWM AMm } \\
& \text { RT-RO whromin } \\
& \text { M.E. Age: } 37 \\
& \text { NO SIGNS OF } \uparrow \text { I.C.P }
\end{aligned}
$$

(cont'd)

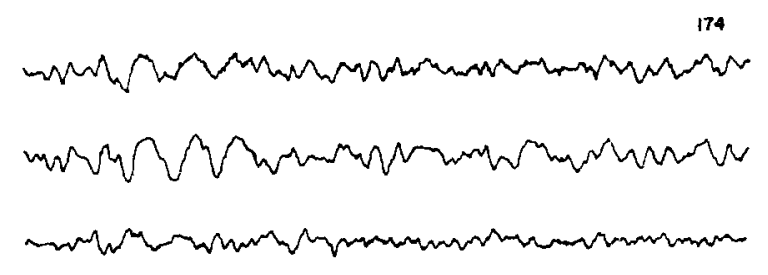

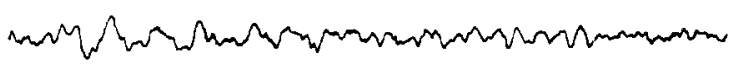
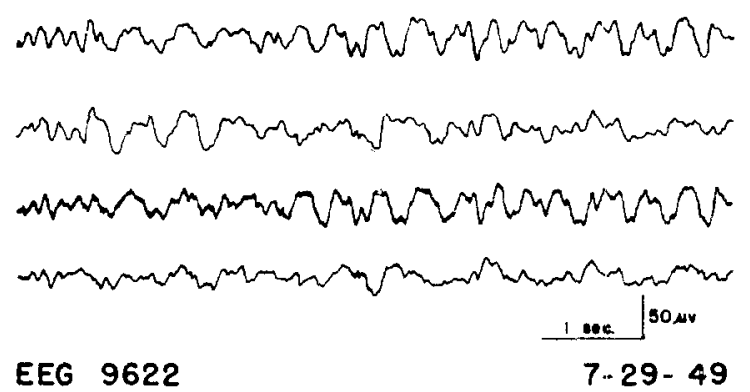

Fig. 3

Large cystic craniopharyngioma in chiasm mainly on the right. Grand mal seizures for one year. Left homonymous hemianopsia. No papilledema nor other signs of increased intracranial pressure. Ventriculogram abnormal without evidence of dilatation of ventricles. Marked bilateral delta bursts anteriorly and posteriorly with right sided emphasis (not shown), and some voltage and wave length and wave form shift between homologous regions (line 1, panel $1 v s$. line 2, panel 2; lines 4 and $6 v s$. lines 5 and 7, panel 2), which was considered preoperatively suggestive of a deep trigger or lesion (see p. 196).

degrees in 8 per cent of deep cerebral lesions (not shown in Table II) can also be contrasted with 45 per cent in infratentorial lesions (Bagchi et al. 1961). Outside of the degree of the shift and antero-posterior variability phenomena; just mentioned, most of the deep non-subfrontal cerebral lesions remain indistinguishable as a group from infratentorial lesions from the standpoint of EEG. This might be expected (Bagchi 1955 b; Van der Drift 1957).

Synchronous bianterior bursts appear to be present oftener than synchronous biposterior bursts (54 vs. $36 \%$ ) in the total series, which is
0.30 ). So it may be maintained that probably IICP is not exclusively responsible for EEG burst phenomenon as is sometimes contended. But there is a significant correlation $\left(X^{2}=9.5, P<0.01\right)$ between burst phenomenon and background slowing. A combination of factors may account for this. Younger age may strike us as one of the factors in the burst phenomenon. Age is significantly correlated with biposterior bursts $\left(X^{2}=10.29, d f=3, P<0.02\right.$ ) but not with bianterior bursts. However, olfactory groove meningiomas in older age group with almost 100 per cent bianterior bursts may have 
overloaded the correlation against age. Bianterior and biposterior bursts are, however, significantly correlated $\left(X^{2}=19.4, P<0.01\right)$. All these facts put together raise the suspicion that it is not the factor of IICP or the age alone, but these and particularly the strategic locations of lesions with relation to other factors thus changing the direction and character of the unstable equilibrium of the entire system.

As mentioned earlier, it has been held by some workers that theta waves are usually associated with deep lesions but our material (not

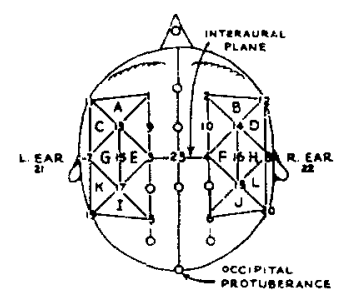

\section{HYPOTHALAMIC GLIOMA} ANT. III VENT. AND CHIASM
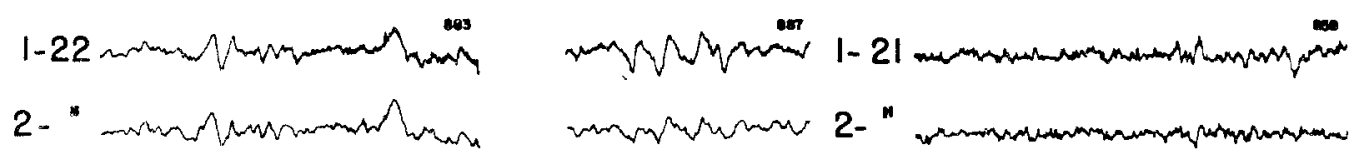

2-"

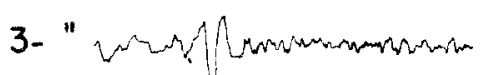

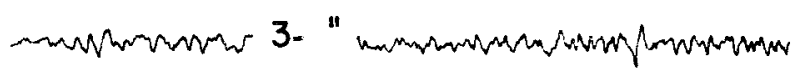

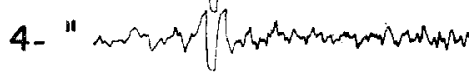

(cont'd)

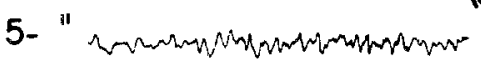

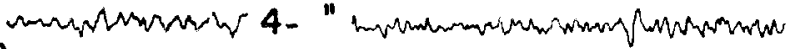

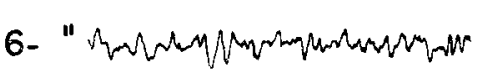

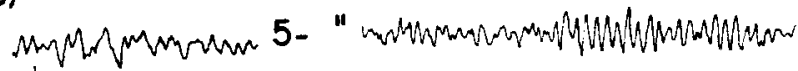

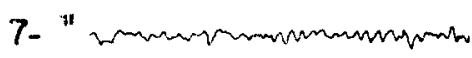

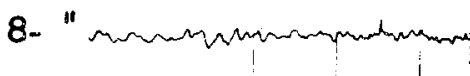

W.B.
PRECEOING AGQ 39
ACTH

EEG $\quad 17990$

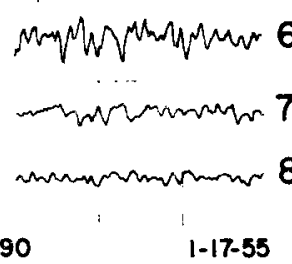

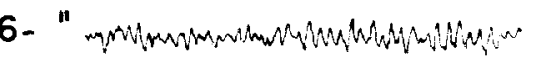

7 - "

8."

Fig. 4

Glioma of the hypothalamus and region of the optic chiasm and mammillary bodies. Headache, weight gain, polyuria and marked mental confusion for one year. No seizures, no signs of increased intracranial pressure. Spinal fluid protein exceeds $100 \mathrm{mg}$ percent. Neurological examination, skull X-ray and arteriogram negative. Endocrine dysfunction according to biochemical studies. First EEG (left and middle panels, 1-17-55) moderately abnormal with many bianterior and also some biposterior theta-delta bursts. Bimotor bursts (lines 3 and 4, left panel) are not due to sleep. These are part of EEG depth signs (see p. 196). Patient's downhill course continued and she was placed on ACTH without clinical benefit. EEG (right panel, 2-25-55), two weeks later, was markedly improved. Patient diẹd three weeks following and came to postmortem.

Note: This is the only case of EEG improvement with known brain tumor in this series. It may be speculated that ACTH might have reduced the edema around the lesion, causing recession of the abnormal EEG signs.

their attendant circulatory changes and preferential discharge arcs relaying the electrical counterpart of these changes that play the dominant role in the causation of EEG burst phenomenon at different locations and background slowing. Variations in EEG findings in particular cases would depend upon which important factor overplays or underplays at a particular time in electronically analysed) does not support this view. Out of 71 cases showing moderate to marked burst phenomenon, 56 revealed primarily delta bursts and 15 theta bursts (not separated in Table II). And in the entire series, theta background slowing (dominant theta or significant theta components - not bursts) in all degrees was present in 68 cases and absent in 49. This 
difference is, however, not large enough to permit any definitive conclusion exclusively in favor of thetas in deep cerebral lesions although many individual cases may show that type of background slowing. (The above figures are not rior theta-delta bursts. Specifically, of all the 16 tumors invading the chiasm without extending to the anterior III ventricle and having field defect and/or atrophy without IICP, only 5 showed biposterior theta-delta bursts (not separated in

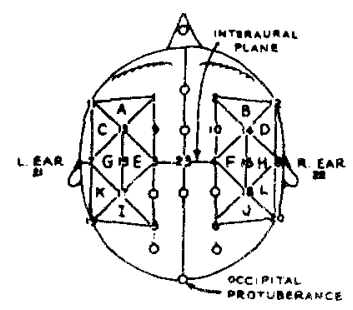

G.B.M.

CORPUS CALLOSUM, R. LAT. VENTRICLE

DEEP FRONTAL LOBES

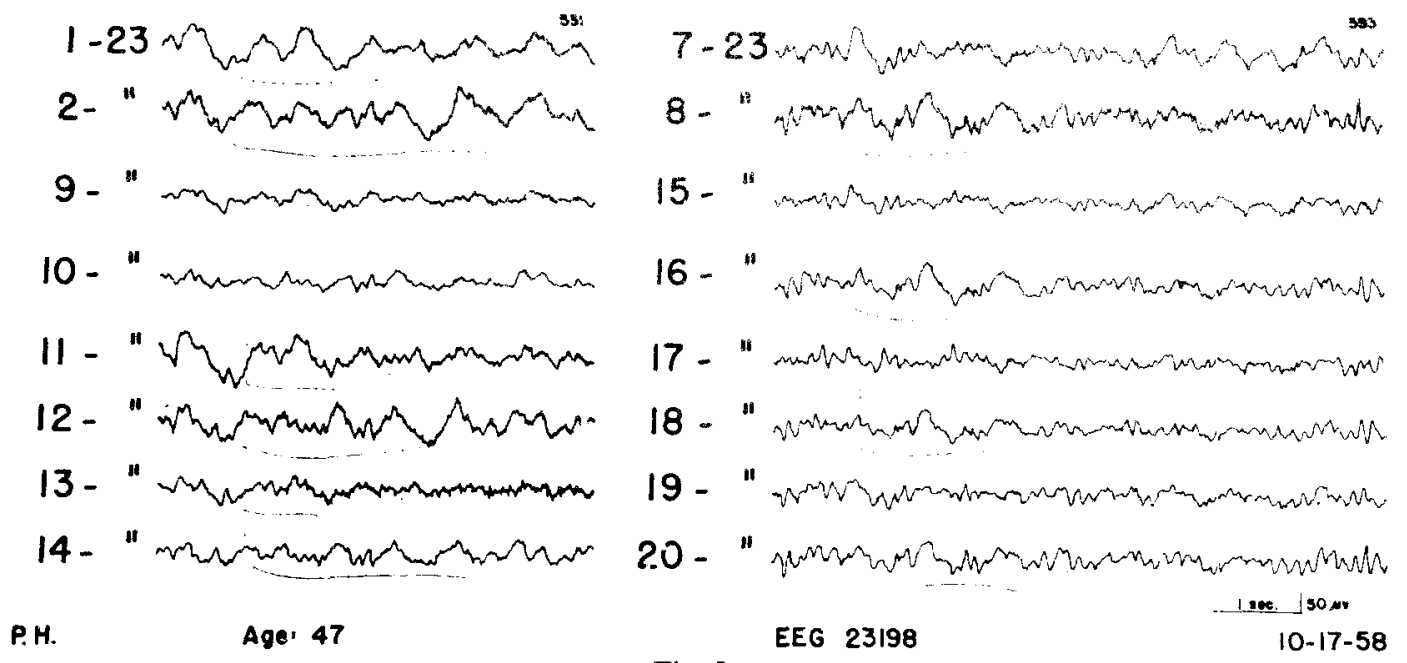

Fig. 5

Extensive glioblastoma multiforme involving the white matter of the right frontal lobe, corpus callosum, right caudate nucleus, and right lateral ventricle with some involvement of the left through the corpus callosum. Two grand mal seizures three months before admission, followed by personality change and confusion. Neurologic examination negative aside from mental change. Skull X-ray, arteriogram, and pneumoencephalogram negative. Moderate increase in cerebral spinal fluid pressure 190 to $210 \mathrm{~mm}$ of water.

EEG is profoundly abnormal with bilateral deltas with very slight right sided voltage and wave length emphasis (fines 2, 4, 8, underlined, right panel). Minimal shift is noted between interaural temporal areas (lines 1 and 2, right panel). These are part of EEG depth signs (see text p. 196).

Note: Here the EEG was the only definitive localizing and diagnostic indication of the focal lesion preoperatively.

limited to moderate to marked background slowing as in Table II, $\mathrm{H}$ and Table III). Only two cases showed medium to high voltage fast background.

No correlation was found between malignancy and degree of EEG abnormality in deep lesions though that probably is not the case with upper convexity lesions (Bagchi $1955 \mathrm{a}, \mathrm{b}$ ). In the entire series the disturbance in the visual system could not be statistically correlated with biposte-
Table II). Again excluding those tumors that had temporal lobe involvement, about half of all tumors (26) invading the chiasm and neighboring regions and producing field defect and/or atrophy had, regardless of the presence or absence of IICP, biposterior bursts and half did not.

\section{DEPTH DIAGNOSIS}

It was possible by using the empirical EEG clues mentioned before (p. 196) to suggest, 
before operation or postmortem, that there was no evidence of a focal upper convexity lesion and that there was deep disturbance or a deep lesion, without any attempt at structure identification. 64 cases $(55 \%)$ were considered as revealing such deep level indications preoperatively, and 21 present. These cases were, however, all correctly lateralized. Thus, a strong unilateral EEG focus tended in a few, but not in the majority of cases, to submerge EEG deep level signs either actually or in interpretation. These 18 tumors were distributed over different deep locations.

\section{OLIGODENDROGLIOMA \\ SUBCORTICAL LEFT FRONTO-TEMPORO-PARIETAL THALAMIC, III VENTRICLE}

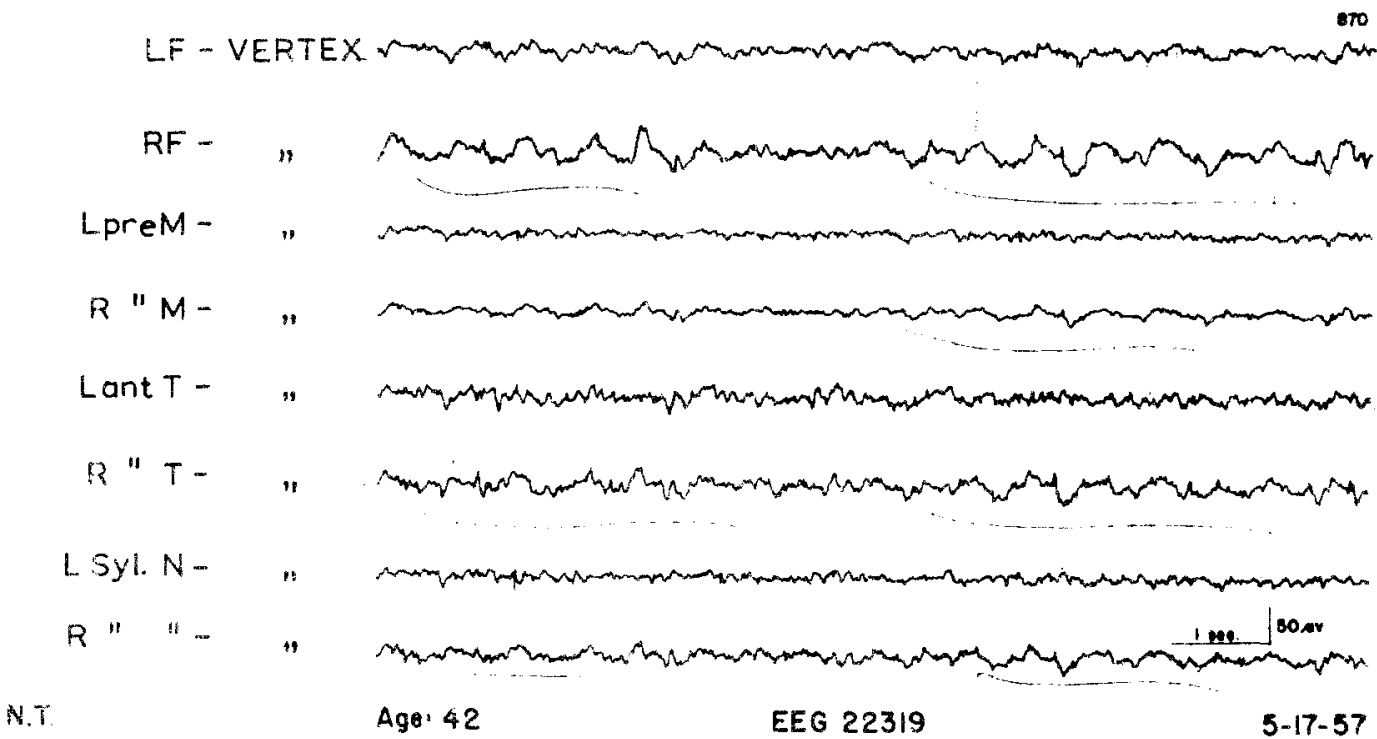

Fig. 6

Huge ofigodendroglioma involving medial basilar area of left temporal lobe and hippocampal gyrus and compressing left thalamus. Postmortem verification. Two weeks" history of headache and vomiting. Left sided pyramidal tract signs. Skull $X$-ray negative. Arteriogram revealed a left sided lesion with shift of vessels to right. Early papilledema, OS.

Definite focal irregular deltas on the right side (lines 2, 4,6 and 8) with little spread to the left. Preoperatively EEG localization was false.

Note: In one epoch only (not shown), with exclusive leit ear lobe monopolar linkage, there was suggestive bilateral multilobar theta, probably due to contamination of left ear by the left temporal lesion. This was not considered in view of the strong right-sided focus. Marked compression effect deeply on the right might explain the deltas on that side but the absent EEG focus on the left is unexplained.

$(18 \%)$ retrospectively (Tables I, III). In the remaining 32 cases $\left(27_{0}^{\circ}\right)$ deep pathology could not be suggested by EEG at any time, though EEG abnormality was present in most of them. In 15 of the last group, EEG's were done prior to 1948 and were, in many cases, inadequate by present standards. Also 18 of the cases not revealing EEG depth signs showed a strong unilateral EEG focus which led to the erroneous impression that a superficial cortical lesion was

\section{DISCUSSION}

It is clear that even wher the cortical mantle is not structurally invaded by lesions lying deep in the brain, abnormal EEG signs are common. A multiplicity of mechanisms and factors are responsible for this. At least two fundamental mechanisms variably interlocked may be considered: (a) neuronal transmission to the cortex of potential changes of deep nuclear masses, 
irritated directly or indirectly by a deep tumor, with attendant imbalance between functionally related regions (Bagchi 1955 a,b; Bickford 1957; Cobb 1957; Faure et al. 1951), and (b) direct functional derangement of the cortex from below by impairment of circulation to it with attendant edema due to the interposition of a deep tumor. There may be other secondary factors, such as tentorial herniation, IICP. Increased in tracranial pressure is not invariably important, as 75 per cent of the 48 cases without IICP showed moderate to marked EEG abnormality. This lack of invariable association between IICP and EEG abnormality has been mentioned by others (Cobb 1944; Cuneo and Rand 1950: Jasper and Van Buren 1953; Williams 1939). The factor of age influences the EEG characteristics as shown before, as may the growth rate of the tumor. The latter could not be assessed. However, at least there is no statistical relationship between the duration of symptoms caused by these tumors and the degree of EEG abnormality in contrast to subtentorial tumors (Bagchi et al. 1961).

If the two above mentioned fundamental mechanisms (i.e., neuronal transmission from below and between upper structures and cortical circulatory deficit) are not operative in the case of a deep tumor, theoretically EEG changes should be nil. It is known that the hypophysis is infiuenced by the hypothalamus releasing neurohumoral substance in it but direct reverse neural (non-humoral) influence of the hypophysis on the hypothalamus or other deep structure is not known, whatever the delayed and indirect humoral effect may be. This may be pertinent to our, and others', observations that some pituitary tumors, cradled within the sella turcica with minimal involvement of the chiasm, produced no, or less, EEG change than tumors in other locations (Magnus and Van der Drift 1957). Olfactory groove meningiomas or other tumors compressing the inferior surface of the frontal lobe cause strong abnormal bifrontal or bianterior temporal bursts. Vertical fronto-orbital fibres, orbito-antero-temporal uncinate fasciculus, associational and callosal fibre systems must be involved in this cortical abnormality caused by these deep lesions (Dr. Elizabeth C. Crosby, personal communication). Why these tumors, even when they functionally impair the chiasm, do not usually relay impulses of irritation to the occipital part of the brain over visual radiations and through the lateral geniculate body and pulvinar or over inferior fronto-occipital fasciculus is not clear. The first relay system may be too indirect. Rarely are there bi-interaural temporal bursts from olfactory groove meningiomas. These discharges may, in part, be mediated by the involvement of inferior aspect of the inferior frontal occipital fasciculus, or may be directly due to compression effect on the medial surfaces of the temporal lobes. The third possibility is the limited transmission from the anterior to the interaura! temporal region. Those chiasmatic tumors that substantially implicate neighboring regions do not show minimal changes.

The role of tentorial herniation in causing EEG changes can not be adequately evaluated becalise in over 40 per cent of the 41 patients who had autopsy the interval between EFG and date of autopsy was too long, one morth to nine months, in 24 per cent, 11 to 30 days. This makes any attempt to relate herniation so the EEC; findings of doubtful value. Of the remaining 36 per cent only one had herniation discovered at autopsy six days after the EEG, which incidentally showed marked changes. Another was found to have herniation 24 days after EFG which also showed some changes, and a few alter a month or more following EEG. The preponderance of autopsied cases without herniation and with EEG done long before autopsy makes it improbable that tentorial herniation was by and large an important factor in the production of EEG changes in our series.

It is not surprising when III ventricle tumors and median thalamic tumors show EEG abnormality since, in these cases, disruption of activity within the diffuse thalamic projection system is likely to play its role in influencing the cortex. But it is surprising when EEG abnormality is not outstanding in the presence of a large thalamic tumor or III ventricle tumor invading or compressing the thalamus, as has been reported in the literature. It is difficult to ascertain whether such was the case due to the physical attenuation of deep poiential changes by the intervening mass of conductive but inactive tissue, or whether the EEG changes were occasional and hence missed, due to short sampling or limited EEG technique, 
or whether some other factors, such as differential irritation of the thalamus, are involved. The physical attenuation would not be a satisfactory explanation because it does not answer: why there would be most attenuation in one deep lesion and not in another located in about the same place. In our series, no thalamic tumor was associated with a normal EEG. The mechanism of so-called "distant rhythms" still needs further clarification." Also, whether the phenomenon of shift and that of interareal variability are special variants of "distant rhythms" and not simply meaningless random events will, for the present, remain open questions. Biposterior theta-delta bursts in a few tumors invading the chiasm but not the III ventricle and not producing IICP will remain another unexplained problem, if one exonerates the visual radiation - lateral geniculate - occipital circuit, which we had to do in a large number of such cases (p. 204). One could implicate, for an explanation, the inferior fronto-occipital fasciculus but the negative cases would ofier a deterrent from doing so.

It is of interest to the electroencephalographer, and definitely useful to the clinician, to be able to exclude, on the basis of EEG clues, existence of a superficial lesion and to suggest the presence of a deep disturbance, including a structural lesion deep in the brain. As mentioned under Materials and methods, different clinical conditions would restrict such a diagnosis. These conditions may give simulated depth signs Bagchi et al. 1952; Cordeau 1959). While it may be contended that depth diagnosis by EEG does not have the same clarity as the focal diagnosis by EEG of an upper convexity lesion, depth diagnosis ceases to be misleading if previously mentioned clinical reservations are observed, and a cautious evaluation made and reported on the basis of data adequately gathered. A false positive finding is as undesirable as, if not more than, a false negative finding. It should be kept in mind also that sometimes it is not possible to distinguish between a "surgical" EEG focus and "non-surgical" EEG focus or patho-physiological trigger, either deep or superficial, which appears for a time and disappears after a few months or years. So no mis-

1 These rhythms are distant only in the sense that the primary cause lies at a distance, but in reality they are cortico-subcortical manifestations. leading EEG statement need be made which may disturo the expectation of a multidimensional approach to a final diagnosis.

\section{SUMMARY AND CONCLUSION}

117 patients with verified deep cerebral tumors were studied qualitatively and statistically in relation to 60 clinical and EEG variables. 92 patients had moderate to profound EEG abnormality. The need for adequacy of EEG technique was stressed. Some of the faciors causing so-called "distant rhythms" were analyzed.

Statisticaliy significant relationships were present between increased intracranial pressure on the one hand and mental changes, age (downward age gradation) or background theta-delta slowing on the other; between age on the one hand and background theta-delta EEG slowing or biposterior EEG theta-delta burst phenomenon on the other; between bianterior and biposterior burst phenomena. No statistical relationships existed between increased intracranial pressure, on the one hand, and location of tumors, bianterior bursts, biposterior bursts, or thalamic involvement on the other; between background theta-delta slowing and thalamic involvement or anterior or posterior burst phenomenon; between duration of symptoms and degree of EEG abnormality; between age and bianterior bursts. Implications of these correlations are discussed. Particular cases may behave contrary to expectations that these correlations suggest, and show unexplained aberrant signs. Though inany factors are independently or cumulatively involved, the strategic location of deep tumors, not necessarily thalamic, is considered one of the most important in the disruption of electro-cortical activity.

Much larger proportion of olfactory groove meningiomas was shown to have bianterior EEG delta abnormality than intra-sellar or restricted chiasmatic tumors. There are various degrees, types and distributions of EEG abnormality in ventricular and white matter tumors. Deep lateral tumors which usually show EEG lateralization may mask EEG depth signs. These EEG depth signs have been empirically structured for aiding interpretation (p. 196). It is contended that within certain clinical reservations these 
EEG depth signs, though not having the same clarity as upper convexity focal signs, have been definitely helpful in ruling out a focal upper convexity lesion and ruling in a deep level disturbance or lesion without structure identiflcation in about three-fourths of the proved cases.

\section{REFERENCES}

BAGCHI, B. K. Pre-operative electroencephalographic localization of brain tumors. Chapter 18 , in T. SHEDLovsky (Editor) Elestrochemistry in biology and medicine. Wiley and Sons, New York, 1955a, pp. $33 !-35 !$

BAcicm, B. K. Electroencephalographic iocalization of intracranial tumors. Chapter 3 in E. A. KAHr, R. C Bassett, R. C. SChNeiner and E. C. Crosby (Editors). Correlative nestrosurgery. C. C. Thomas, Springheld, III., $1955 b$.

BaGChI, B. K. and Basset, R. C. The focalization of intracrarial lesions by EEG. Univ. Mich. Hosp. Bull. $1943,9: 8687$.

BaGCH, B. F. and BASSETT, R. C. Soms additional EEG techniques for the localization of intracranial lestons. j. Nouroswg 194\%, 4: 348-369.

BAGCH. B. K., Howel, R. W. and SCHMALE, H. R. The EEG and clinkat effects of electrically indued con. visions in the treatment of mental disorders. Appendix. Amer. J. Psychiat, 1945, 102: 49-61.

Bacichi, B. K., KoOt, K, A., SeIvNG, B T, and CaLHoUN, H. D Posterior fossa lesions: An EFos study of

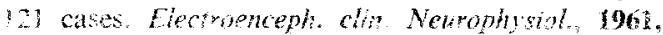
13: :80-:92.

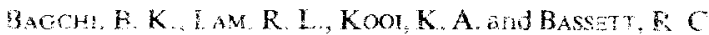
LCG findings in posterior fossa tumors. Electroncepl Hir. Necuphysiol. 1952, 4:23-40.

BICKEORD. K. G. FEG diagnosis of brain tumers Amer x. Surg. 1957,93:946-951.

Broglia, S. and Postr, A. Comparatve EEG cildies of subtentoria! and third ventricle tumours. Mikerra Chir Tonino, 1956a, it:457-460.

BROGLis, S. and POSvR, A. EEG aspects of 100 immors of the posterior fossa and 40 of the third ventricle. $k i$ Nearol, 1956h, 26: 26.50.

BuC, P. C. and CASE, $T$. I An association between homonymous hemianopsia and unilateral absenee of the aloha waves. Trans. Amer. neurol, Ass., 1940, 66: $17-20$.

CASE. T. 3. Association of homonymous hemianopsia and unilateral absence of alpha waves. Arch. Neurol Psychiat. (hicago) 1940, 43:1273-1274.

Conri, W. A. The electroencephalographic localization of iniracranial neoplasms.j. Neurol. Neturosurg. Psichiat, 1944, $7: 96-102$

CoBs, W. A. Electroencephalographic abnormalities as signs of iocalized pathology. EEG abnormalities at a distance from the lesion. Quatrieme Cong. Intern Electroencéphi. Neurophysiol clin., (Bruxelle.s) 1957, pp. 205-223.

COBe, W. A. and Muller, G. Parietal focal theta rhythm.
Electroenzeph. clin. Neurophyiol., 1954 6: 455-460.

CORDEAU, I. P. Monornythmic frontal delta activity in the human EEG: a study of 100 cases. Electroenceph. clir? Neuropinysiol., 1959, il: $733-746$.

Cunfo, H. M and Ravd, CW. Analysis of FEu findings in 40 cases of verified train tunours. Bull. Los Angeles neurs. Soc., 1950, 15:22 36.

DaIY, D. D. and Thomas, J. E. Sequential alterations ir the EFG of patients with brain tumours. Electro e'tcepis. cin. Newophysiof, 1958, 10; 395-404.

DAIY, D. WHECAN, I. L., BICKFOKD, R. G. and MAC CART, C. S. The EEC in cases of thmours of the posterior fosse and thind ventricic. Electrocteph. chin. Neikophysiot. 1953, 5:202,216.

DRIF?, I. H. A VAN DER. The rignifieance of electroen. cepholography for the lizgnosis and focalization of

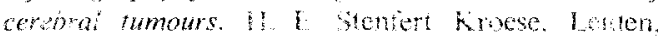
1957.

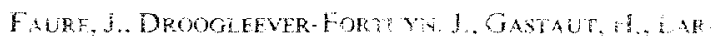

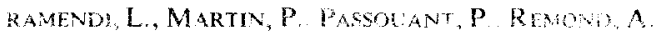

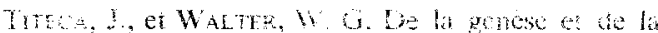
signitiation des rythes catelis a distuce an ko cas de tumears cebondos. Flevenenceph ain Neuraphysiol., 1951, 3:499+34

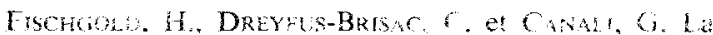
reaction darrêt dans les tumeurs oceipitales. parécales atemporales. Rev peuroi, 1949, *i: 51653 ?

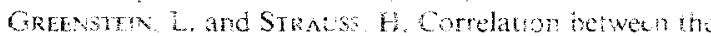

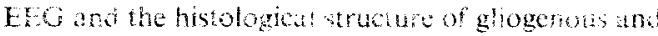

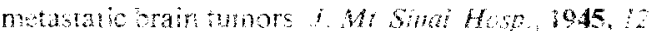
$878 \%$

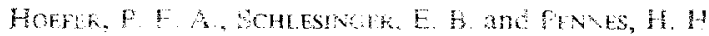

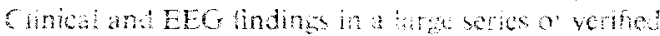
bran tumos Discussion on mater Tran. Anet

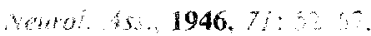

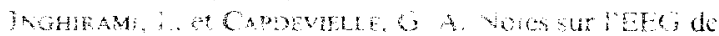

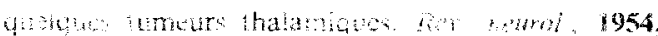
$4: 52125$

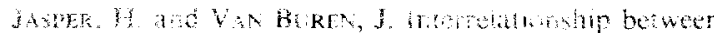

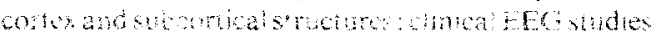

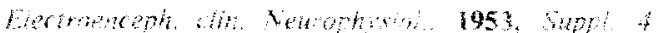
ite ing

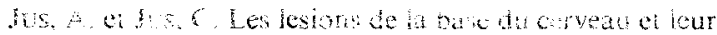
exprestan dectrocténtalographaue. Paris mid. $1947, ? 593-595$

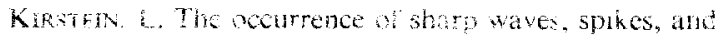
hast athity in suplatentorial tumours. Fectroneph. dir Newronisioi, 1953, 5, 33-40

Ki Ass, D. W and BrCKForD, $R, G$. The EEG in metastatic

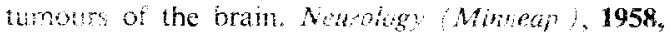
$8: 333-33$ ?

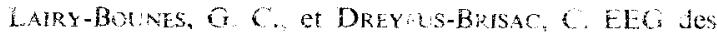
tumeura hémisphériques intra o sous ventriouiares. Rev. hetura 1950,83:613\%618

EAm, R. L. An unusua! electroenephalogram associated with thatamic tumor Electroencept. tin. Nesirs physiol, 1950, 2: 329-330.

LAUFER, M. W. Some electroencephatographic findings in subcortical and hypothalamic lestons. J. nerv. ment. Dis., 1947, 106: 527-536

Loeb, $C$ and Poggio G. F. Distribution and character. 
istics of the electrical rhythms of the brain in 100 cases of supratentorial tumors. Riv. Neurol, 1953, 23: $481-486$.

LONDONO, R. EEG in adenomas of the hypophysis and in cranopharyngiomas. Neurocirugia, 1957, 15: $50-53$.

Longo, P. W., Pupo, D. P., Pazzanese, O. et Pimenta, A. M. Résultats électroencéphalographiques dans 33 cas de tumeurs intra-craniennes chirurgicalement vérifiés. Arch. Neuro-psiquiat S. Paulo), 1950, 8:43-46.

MAGRUS $O$, and VAN DER DRiFT, J. H. A. The significance of the EEC for the diagnosis and localization of cerebral tumours. Folia psychiat, neerh, 1957, 60: $118-125$.

MCDOval. C. A and Kors, M. Brain tumor with normal brain potentials. R.I. med. J., 1940, 23:111-113.

Parllas. J. E., Gastaut, H., 'Tamalet, J. et Verspick. Valeur de l'électroencéphalographic pour la diagno:tique des tumeurs cérebrales. Presse méd., 1948, 56: $851-853$.

PARAT, I. Valeur localisatrice de l'EEG dans ies tumelirs de la fosse antérieure. Rev. Neurol., 1948, 80:627-628.

PAylovski, Y. M. Some problems on the subject of diagnosi: of tumors of the base of the frontal region. Nevropat. i Psihiat. 1958, 58:521-525.

Sapkisov, S. A. and Penzik, A. S. The electroencephalogram in cases of cerebral tumors. Acta med. URSS, 1939, 2: 185-190.

SCHLESTnger, B. and Strauss, H. Comparison of pnelimoencephalography and electroencephalography in brain tumors. J. Mi Sinai Hosp. 1947, 14:47-50.

SilvermaN, D. and GrafF, R. A. Brain tumor depth determination by electrographic recordings during sieep, Arch. Neurol. Psychiat. (Chicago), 1957, 78: $15-28$.

Steinmann, H. W. und Tönnis, W. Das EEG bei intra- kranieilen raumbeengenden Prozessen. Zbl. Neurochir. 1953, 13: 129-146.

StePHENSON, W. A. Intracranial neoplasm associated with 14 and 6 per second positive spikes. Neurology (Minneap.), 1951, 1 : $372-376$.

Terzian, H. and Cecotto, C. Electroencephalograrns in tumors of the basal nuclei regions. Riv. Naurol., 1954, 24: 752759

Tönis, W., STenvana, H.W. und Krenker, W. Elektroencephalographische Befunde bei 44 Tumoren der Sellagegend. Acta neuroveg. (Wien), 1953, $5: 29$ :-305.

Walter, W. G. The localization of cerebral tumors by EEG. Lancet, 1936, 2: 305 308.

WALTER, W. G. The EEG in cases of cerebral turnors. Proc. royal. Soc Med., 1937, 30: 579-598.

WALTER, W. G. Electroencephalography in the diagnusis of cerebral tumor and abscess Pract oto-hino-larng. (Basel), 1940, 3: 17-26.

WALTER, W. G. and DOVEY, V. J. Electroencephalography in cases of subcortical tumor. $J$. Neurol. Neurosurg. Psychiat., 1944, 7:57\%65.

WALTER, W. G., Griffiths, G. M. and Nevin, S. The electroencephalogram in a case of pathological sleep due to hypothalamic tumor. Brit, med. J. 1939, I:107.

Williams, D. The abnormai cortical potentials associated with high intracranial pressure. Brain, 1939, 62:321334.

Williams, D. and Gibes, F. A. Localization of intracranial lesions by EEG. Arch. Neurol. Psychat. (Chicago), 1939, 4l:519 534.

YeAger, C. L. and LuSE, S. Electroencephalographic localization and differentiation of lesions of frontal lobes with pathological confirmation. Arch. Neurol. Psychiat. (Chicago), 1945, 54: 197-201.

Reference: Small, J. G., Bagchi, B. K. A. and KooI, K, A. Electro-clinical profile of 117 deep cerebral tumors. Electroenceph. clin. Neurophysiol., 1961, 13: 193-207. 